ARTIGO

\title{
Ampliação da obrigatoriedade escolar no Brasil: o que aconteceu com o Ensino Médio?*
}

Monica Ribeiro da Silva a

\section{Resumo}

O artigo é resultado de uma pesquisa, que teve como objeto de estudo a ampliação do direito à Educação, considerando o acesso ao Ensino Médio para jovens de 15 a 17 anos. Tem como referência legal o que determinam a Constituição Federal, a partir da Emenda Constitucional n ${ }^{\circ}$ 59/2009, a Lei de Diretrizes e Bases da Educação (Lei no 9.394/1996) e o Plano Nacional de Educação 2014-2024 (Lei $\left.\mathrm{n}^{\circ} 13.005 / 2014\right)$. Considera que um pressuposto para a universalização do acesso à Educação é a condição da obrigatoriedade escolar. É analisado o movimento da matrícula na última etapa da Educação Básica, no período compreendido entre 2009 e 2016. As fontes primárias para coleta dos dados foram o Censo Escolar da Educação Básica e a Pesquisa Nacional por Amostra de Domicílio (Pnad), apreciando as 27 Unidades da Federação. A análise indica que houve, no período, um processo de inclusão educacional da faixa etária, sobretudo nos estados que apresentavam maior exclusão. Nas redes estaduais, o aumento médio da matrícula foi de $12,7 \%$ e na rede federal de $102,4 \%$.

Palavras-chave: Ensino Médio. Educação Básica. Obrigatoriedade escolar. Inclusão educacional. EC 59/2009.

\section{Introdução}

Ao completar 10 anos, a Emenda Constitucional (EC) n n 59/2009 encerra um imenso desafio no que se refere à democratização do acesso à Educação Básica no Brasil. Dentre suas determinações, restou estabelecido que todas as pessoas entre 15 e 17 anos deveriam estar matriculadas em uma das etapas educacionais até 2016. Em vista disso, este artigo propõe-se a fazer um balanço do movimento em direção à ampliação do acesso ao sistema escolar, considerando a particularidade

\footnotetext{
* Pesquisa financiada pelo Conselho Nacional de Desenvolvimento Científico e Tecnológico.

a Universidade Federal do Paraná, Curitiba, PR, Brasil.
} 
do Ensino Médio, haja vista que a mudança constitucional sinaliza para o seu reconhecimento como direito.

Dentre os motivos que levaram à realização da análise, está a constatação de que a matrícula na última etapa da Educação Básica decai progressivamente a partir de 2004. O Ensino Médio, que, ao final do século XX, contava com pouco mais de 3 milhões e 500 mil matrículas (menos de $25 \%$ da faixa etária em idade apropriada) chega em 2004 ao ápice de, aproximadamente, 9 milhões de pessoas matriculadas, o que correspondia a pouco mais de $50 \%$ dos indivíduos entre 15 e 17 anos. A partir desse período, assiste-se à diminuição desse quantitativo, ano após ano, chegando, em 2017, a um total abaixo dos 8 milhões. O que essa diminuição significa em um contexto em que a legislação sinaliza para a ampliação do direito à Educação para a faixa etária considerada apropriada para estar no Ensino Médio? Essa pergunta motivou a investigação realizada, com o objetivo de produzir uma aproximação com a realidade identificada nos dados do Censo Escolar.

Parte-se do pressuposto de que os direitos sociais são construções históricas (BOBBIO, 1992). Nessa perspectiva, sua origem está fundamentada também nos aspectos conjunturais que prenunciam sua afirmação. Outro aspecto relevante para situar essa questão está em Chauí (1989), quando assinala: "cada direito, uma vez proclamado, abre campo para a declaração de novos direitos" e "essa ampliação das declarações de direitos entra em contradição com a ordem estabelecida" (p. 26). A par dessa assertiva, ainda com base na autora, é possível considerar que a proclamação, de certo modo, constrange a realidade, na medida em que, naquele dado contexto, só se realiza em função da sua inexistência, ou seja, do seu não cumprimento ou de sua postergação. Por outro lado, Ferrajoli (2002), assevera que uma norma só pode ser considerada vigente quando estiver em consonância com o já estabelecido. A controvérsia acerca da natureza dos direitos sociais ilustra as tensões que cercam o assunto e impele a que sejam perscrutadas à luz de seus enunciados e da realidade encontrada.

O direito à Educação escolar no Brasil encontra-se firmado na Constituição Federal (CF) de 1988 e na legislação específica do campo educacional. A Carta Magna traz em seu Art. $5^{\circ}$ a Educação como um direito social, juntamente com a saúde, o trabalho, o lazer, a segurança, a previdência social, a proteção à maternidade e à infância, e a assistência aos desamparados. Pela EC n ${ }^{\circ}$ 26/2000, foi acrescido o direito à moradia, e pela $\mathrm{EC}$ n $^{\circ}$ 64/2010, o direito à alimentação. No Capítulo III - "Da Educação, da cultura e do desporto", na seção I - Da Educação, a CF, no Art. 205 explicita a Educação como direito de 
todos e dever do Estado e da família. No Art. 206 são elencados os princípios sob os quais ela deve ocorrer, dentre eles: a igualdade de condições para o acesso e permanência na escola; a gratuidade do ensino em estabelecimentos oficiais; a valorização dos profissionais do ensino.

Silveira (2013) alerta para o fato de que a Educação, por se tratar de um direito de natureza social, extrapola a tutela individual. É isso o que permite sua exigibilidade, inclusive pela via judicial. A autora mostra, ainda, que o não cumprimento do disposto em Lei tem sido argumentado, principalmente, com relação "à falta de recursos; impossibilidade de interferência do Judiciário no poder discricionário do Executivo; ações envolvendo a formulação e a implementação de políticas públicas por meio de pedidos que abrangiam com interesses difusos e coletivos" (p. 373). No entanto, conforme estabelece a própria Constituição Federal, em seu Art. 208, § $1^{\circ}$, a Educação escolar obrigatória é direito público subjetivo, sendo de competência e responsabilidade do Estado e da família, não cabendo, portanto, ao Executivo o poder de escolha sobre sua oferta ou alegação de dificuldades que impeçam que ela ocorra. Os dispositivos constitucionais asseguram, assim, a exigibilidade do direito.

Se a década de 1990 impôs que se envidassem esforços para garantir a universalização do Ensino Fundamental, alçado a obrigatório dos seis aos 14 anos pela Lei $\mathrm{n}^{\circ} 10.172 / 2001$ (BRASIL, 2001), que estabelecia o Plano Nacional de Educação 2001-2011, uma vez atendida a ampliação do acesso e da permanência nessa etapa, o final dos anos 2000 trazia a possibilidade de que se projetasse novo alargamento do direito. É o que faz a EC n ${ }^{\circ} 59 / 2009$, firmando a obrigatoriedade escolar dos quatro aos 17 anos. De acordo com Oliveira, o sentido da obrigatoriedade compreende um duplo dever: "A dupla obrigatoriedade refere-se, de um lado, ao dever do Estado de garantir a efetivação de tal direito e, de outro, ao dever do pai ou responsável de provê-la, uma vez que passa a não fazer parte do seu arbítrio a opção de não levar o filho à escola" (2002, p. 15). É com base nessas prerrogativas da afirmação do direito que se realiza a análise das informações coligidas na pesquisa.

Com vistas a interpretar os dados da oferta do Ensino Médio para a faixa em idade escolar obrigatória e desejada para a etapa, dois conceitos se mostraram centrais: progressividade e inclusão, conforme Viñao (2002). Ao estudar o comportamento dos sistemas escolares ao longo do século XX, o autor identifica a ocorrência de inclusão (ou exclusão), de progressividade e de segmentação. A inclusão diz respeito "ao índice de acesso e uso global por uma determinada população de um nível, ciclo, etapa, curso ou tipo de ensino" (VIÑAO, 2002, p. 37). Os dados 
estatísticos que aferem esse índice estão circunscritos à participação de cada grupo etário em cada um desses níveis, etapas ou ciclos. O contrário seria a exclusão, isto é, a ausência de acesso, segundo a faixa etária. Por progressividade se há de entender, também conforme Viñao (2002), a aferição do grau em que alunos de determinado nível, ciclo, estágio ou tipo de ensino pertencem às classes média e baixa. Trata-se, assim, do índice que representa a distribuição, pelo sistema escolar, de estratos, classes ou grupos sociais de uma população dada. Além desses dois conceitos, Viñao (2002) atenta para a ocorrência de segmentação, que ocorre quando os processos de inclusão e progressividade são acompanhados da instalação de dois ou mais ramos ou métodos de ensino diferenciados, conforme os grupos sociais que acessam o sistema escolar. No caso do Ensino Médio brasileiro, a histórica dualidade entre formação geral, propedêutica e a formação técnica e profissional é emblemática do processo de segmentação e se institui ao longo do tempo como um mecanismo capaz de reforçar as desigualdades escolares. No entanto, os dados coligidos na presente pesquisa permitem discutir, apenas no terreno das hipóteses, a existência de segmentação quando da ampliação do acesso ao Ensino Médio no período estudado.

A pesquisa considerou, também, a análise realizada por Krawczyk e Silva (2017). Os autores se apoiam, igualmente, em Viñao (2002) para afirmar que o sistema escolar contribui com a produção das desigualdades escolares por meio dos três mecanismos mencionados - inclusão, progressividade e segmentação. Para eles, o conceito de progressividade é utilizado para caracterizar "a capacidade de incluir no acesso à escola setores sociais mais pobres, vulneráveis e em situação de exclusão social" (KRAWCZYK; SILVA, 2017, p. 4). Já por inclusão, entenderam como sendo a "capacidade que os sistemas de ensino têm para garantir a oferta de matrículas nos vários níveis de ensino, de acordo com o tamanho da população em idade escolar", o que os leva ser "mais ou menos desiguais se sua capacidade de oferta de matrículas não for suficiente para atender as demandas por escolaridade em cada contexto" (KRAWCZYK; SILVA, 2017, p. 5). No trabalho mencionado, os autores se propuseram a estudar as desigualdades educacionais, considerando a possibilidade de ocorrência de progressividade. O diagnóstico do perfil socioeconômico dos inscritos no Exame Nacional do Ensino Médio (Enem), no período de 1998 a 2014, levou à conclusão de que estaria se verificando "uma maior representação de setores sociais que são considerados mais vulneráveis e em situação de exclusão nas estruturas sócias brasileiras (p. 21).

Em face da obrigatoriedade escolar para a faixa etária de 15 a 17 anos, estabelecida em 2009, a expectativa de ampliação do acesso passa a compor a pauta da política educacional, o que se verifica, sobretudo, na redação dada 
ao Plano Nacional de Educação, em 2014. Em vista disso, a pesquisa, da qual resulta o presente artigo, priorizou a análise dos dados de matrícula no Ensino Médio para essa idade, considerando o período 2009-2016, anos demarcados para inclusão escolar de toda a faixa etária, considerando a oferta pelas redes públicas estaduais e federal. Para isso, em um primeiro momento, procedeu de modo a considerar os dados da oferta do Ensino Médio entre 2001 e 2009 e, posteriormente, entre 2009 e 2016 . Os dados foram desagregados, segundo a faixa etária (15 a 17 anos), e a oferta pública nas dependências administrativa estadual e federal, com vistas a discuti-los à luz do conceito de inclusão escolar, e identificar indícios de progressividade; por último, a proposta foi a de levantar e analisar a série histórica dos dados de matrícula na modalidade de formação geral e de Educação profissional técnica de nível médio para o período 20092016 e para as 27 Unidades de Federação e problematizá-los à luz do conceito de segmentação escolar.

\section{O movimento geral da matrícula no Ensino Médio: um histórico que justifica a Meta 3 do Plano Nacional de Educação 2014-2024}

Uma das características históricas do Ensino Médio diz respeito ao abandono e à exclusão educacional. Ao final do século XX, menos de $25 \%$ das pessoas em idade considerada apropriada, estavam matriculadas (GOMES, 2000). Observa-se um crescimento expressivo entre 1991 e 2004, como visto. A partir de 2004, passa a haver decréscimo, mantendo-se praticamente inalterada na faixa das 8.300 .000 até 2014 , para, então, voltar a decrescer (2015 conta com 8.076.150 e 2016 com 8.133.040 matrículas). Em 2017, o total de matrícula ficou abaixo de 8 milhões (INEP, 2016, 2017a).

Krawczyk e Silva (2017), com base em Oliveira e Araújo (2005) e Brito (2014), explicam o aumento progressivo da matrícula no Ensino Médio, a partir de alterações ocorridas no Ensino Fundamental, dentre elas, as políticas de correção do fluxo escolar dos anos de 1990, que teriam contribuído para o aumento da taxa de conclusão e, consequentemente, impulsionado a ampliação da procura pelo Ensino Médio. O aumento da conclusão no Ensino Fundamental deu-se, majoritariamente, dentre setores, até então, excluídos do sistema escolar. Para os autores, "este fenômeno aponta também para tendências gerais que marcaram o deslocamento da seletividade escolar no país para níveis mais altos, desta vez centradas, sobretudo, no Ensino Médio e superior" (KRAWCZYK; SILVA, 2017, p. 2). 
Em se tratando do Ensino Médio, o crescimento expressivo ocorreu na rede pública. A matrícula na rede privada se mantém praticamente inalterada em números absolutos, de 1991 a 2014, com um crescimento da ordem de $10,3 \%$. Se no início desse período, a oferta privada correspondia a $27 \%$ do total, em 2014 corresponde a 11,8\%. A matrícula apresenta-se concentrada na dependência estadual, que passou de 2.472 .964 (65,5\%), em 1991, para 7.026.754 (85,5\%), em 2014. Entre os anos de 2009 e 2014, ano de aprovação da Lei do Plano Nacional de Educação, a matrícula total do Ensino Médio (considerando todas as faixas etárias) tem um decréscimo da ordem de $0,8 \%$. A matrícula do Ensino Fundamental, anos iniciais, decresce 10,9\%, e dos anos finais diminui em $11,8 \%$, no período. A taxa decrescente no Ensino Fundamental explica, ao menos em parte, a diminuição da matrícula também na última etapa da Educação Básica.

Na pesquisa ora relatada, foi analisada a taxa líquida de matrícula para um período ampliado (2001-2014), com vistas a dimensionar e caracterizar, regionalmente, o processo de inclusão. Os dados evidenciam o aumento da presença de pessoas de 15 a 17 anos em todas as regiões do país, sobretudo nas regiões mais pobres e menos industrializadas. Isso indica que a diminuição do número absoluto de matrícula se deu dentre as pessoas com 18 anos ou mais, e, por outro lado, evidencia um processo crescente de inclusão.

Com base nos dados do Censo Escolar e da Pesquisa Nacional por Amostra de Domicílio (Pnad), desse intervalo temporal, é possível afirmar que o país passa de um acesso extremamente desigual no Ensino Médio para um acesso menos desigual, caracterizado, inclusive, pela diminuição expressiva dessa desigualdade entre as macrorregiões. O crescimento da taxa líquida de matrícula em cada uma das regiões do país foi da seguinte ordem: Norte, de $43 \%$ para $51,2 \%$; Nordeste, de 43,3\% para 53,0\%; Sudeste, de 66,1\% para 69,4\%; Sul, de 59,6\% para $63,9 \%$ e Centro-Oeste, de $56,7 \%$ para $63,4 \%$. Esses dados revelam que a inclusão das pessoas de 15 a 17 anos no Ensino Médio foi mais expressiva nas regiões Norte e Nordeste, justamente as que tinham a taxa líquida de matrícula abaixo dos $50 \%$, sinalizando para um movimento de progressividade, dado que se tratam de regiões mais pobres e menos industrializadas. Se considerarmos o período 2001-2009, o aumento expressivo da taxa líquida de matrícula nas regiões Norte e Nordeste evidencia inclusão com indício de progressividade, haja vista a expansão do acesso ao Ensino Médio nas regiões mais pobres do país. Vale destacar o Estado do Tocantins, que passa de uma taxa líquida de matrícula em 2001 de 33,4\% para 60,1\%, em 2009 (Censo Escolar da Educação Básica; vários anos). 


\section{O acesso das pessoas de 15 a 17 anos ao Ensino Médio a partir de 2009: tensões diante do cenário de ampliação do direito à Educação}

Ao compreender o Ensino Médio como etapa da Educação Básica, a LDB $\mathrm{n}^{\circ}$ 9.394/96 (BRASIL, 1996) confere-lhe o sentido de direito fundamental, mas, contraditoriamente, não lhe assegura a condição de ser etapa escolar obrigatória. A ampliação da obrigatoriedade escolar, posta pela EC $n^{0} 59 / 2009$, que inclui a faixa etária de 15 a 17 anos, justifica o estabelecido na Meta 3 do Plano Nacional de Educação (PNE) 2014-2024 quanto à universalização do atendimento em 85\% para o final da vigência do Plano.

O país contava, em 2012, com uma população de 10 milhões e 500 mil jovens de 15 a 17 anos, aproximadamente (IBGE, 2017), porém, destes, apenas 5.451.576 frequentam a última etapa da Educação Básica (pouco mais de $50 \%$ ). Naquele ano, somavam 2.464 .422 os jovens dessa idade matriculados no Ensino Fundamental regular, o que correspondia a 23,6\% da faixa etária. Não possuíam qualquer vínculo escolar e não haviam concluído o Ensino Médio um total de 1.578 .562 jovens $(15,2 \%)$ em idade escolar obrigatória e apropriada para estar no Ensino Médio. No ano de 2014, ano de aprovação do PNE, a população com essa idade compreendia um total de 10.613.209 pessoas (IBGE, 2017). Destas, 1,6\% eram analfabetas, 17,4\% (1.841.783) estavam matriculadas no Ensino Fundamental, 55\% (5.842.464) no Ensino Médio, 1,6\% (162.763) na Educação de Jovens e Adultos. Em 2014, um total de 1.713.569 $(16,1 \%)$ jovens entre 15 e 17 anos não possuíam qualquer vínculo escolar e não haviam concluído o Ensino Médio; 714.494 (6,7\%) não estudavam, mas haviam concluído o Ensino Médio. Matriculados no Ensino Superior estavam 307.350 pessoas (2,9\%) (INEP, 2017a). Entre 2014 e 2016, a situação alterouse com um ligeiro aumento da inclusão da faixa etária no Ensino Médio, porém, o percentual de pessoas sem qualquer vínculo escolar permanecia além do 1,5 milhão. Em que pese a tendência de queda da matrícula do Ensino Médio, quando comparados o número total da etapa com a matrícula exclusiva para a faixa etária de 15 a 17 anos (taxa líquida), indicam que o decréscimo permanece ocorrendo dentre os que possuem 18 anos ou mais, e que incidiu, para a idade de 15 a 17 anos, um significativo crescimento, caracterizando o processo de inclusão.

Quando considerada a taxa de matrícula das pessoas de 15 a 17 anos, em qualquer uma das etapas da Educação Básica, os dados indicam um processo de quase estagnação. Sem considerar o ano/série em que estão matriculados, 
essa taxa obteve um recuo, passando de $83,3 \%$, em 2013, para $82,6 \%$, em 2014, mesmo patamar de 2012 e 2009 . Se por um lado, o número de jovens entre 15 e 17 anos incluídos no sistema escolar diminuiu no período, por outro lado, é expressivamente maior o número dos que estão matriculados no ano/série esperados, sinalizando uma mudança para melhor no que se refere ao fluxo entre o Ensino Fundamental e o Médio. Evidência disso é o aumento da taxa líquida de matrícula no Ensino Médio, que cresceu de 54,9\%, em 2009, para 62,7\%, em 2016, considerando todos os Estados da Federação. Um aumento de $12,7 \%$ para a situação mencionada, com crescimento da matrícula em todas as dependências administrativas e em distintas modalidades de oferta.

Identificado o crescimento da taxa líquida de matrícula, interessava, para os objetivos da pesquisa, caracterizar a distribuição pelas redes estaduais, considerando todas as Unidades da Federação para o período 2009-2016. Os dados obtidos junto ao Censo Escolar da Educação Básica estão dispostos na Tabela 1 e no Quadro 1.

Os dados da Tabela 1 e do Quadro mostram que a distribuição da matrícula pelas redes estaduais, no período estudado, passou por crescimento em todas as Unidades da Federação, exceção feita ao Rio Grande do Norte. O aumento expressivo entre 2009 e 2016, em estados como Amazonas (42,2\%), Roraima (34,6\%), Acre $(36,8 \%)$ e Pará $(25,7 \%)$, todos da região Norte, é indício de inclusão acompanhada de progressividade, por se tratar de região mais pobre e menos industrializada, em que a taxa líquida de matrícula era consideravelmente mais baixa em relação aos demais estados no período anterior a 2009. Na região Nordeste, o destaque se dá para o estado do Rio Grande do Norte, com crescimento negativo entre 2009 e 2016 (-9,9\%), porém, o estado passou por um aumento expressivo, quando comparado aos demais da região, quando considerada a dependência federal, com ampliação da matrícula na ordem de $246 \%$.

No que se refere à dependência administrativa federal, a taxa de crescimento eleva-se em 102,4\%, para o agrupamento de 15 a 17 anos, no período. A rede federal se desenvolve, sobretudo, na oferta da Educação Profissional Técnica de Nível Médio. No período compreendido entre 1997 a 2015, enquanto a matrícula no Ensino Médio de Formação Geral cresceu 20,6\%, a matrícula na Educação Profissional Técnica de Nível Médio, considerando todas as formas de oferta (concomitante, subsequente e integrado), e nas dependências estadual e federal, cresce $1.309 \%$. Apreciando apenas a modalidade de Ensino Médio Integrado, o crescimento da matrícula entre 2009 e 2016 foi de, aproximadamente, $600 \%$. Isso sugere que a ampliação do acesso ao Ensino Médio, no período, pode ter 
Tabela 1 - Distribuição da matrícula de 15 a 17 anos no Ensino Médio por Unidade da Federação - 2009-2016 - dependência estadual

\begin{tabular}{|c|c|c|c|c|c|c|c|c|}
\hline $\begin{array}{l}\text { UF } \\
\text { RO }\end{array}$ & $\begin{array}{c}2009 \\
37.148\end{array}$ & $\begin{array}{c}2010 \\
38.361\end{array}$ & $\begin{array}{c}2011 \\
42.113\end{array}$ & $\begin{array}{c}2012 \\
41.078\end{array}$ & $\begin{array}{c}2013 \\
41.599\end{array}$ & $\begin{array}{c}2014 \\
41.636 \\
\end{array}$ & $\begin{array}{c}2015 \\
43.767 \\
\end{array}$ & $\begin{array}{c}2016 \\
41.763\end{array}$ \\
\hline$A C$ & 20.031 & 20.756 & 22.467 & 23.754 & 25.875 & 26.289 & 27.231 & 27.406 \\
\hline AM & 80.402 & 79.738 & 86.169 & 92.305 & 99.367 & 103.977 & 107.805 & 114.319 \\
\hline RR & 11.380 & 11.945 & 13.097 & 14.561 & 15.016 & 15.525 & 15.852 & 15.315 \\
\hline PA & 145.188 & 147.006 & 151.745 & 157.833 & 166.847 & 170.819 & 174.476 & 182.521 \\
\hline AP & 20.597 & 205.73 & 20.481 & 21.662 & 21.513 & 22.266 & 23.029 & 23.329 \\
\hline TO & 40.725 & 40.073 & 42.303 & 43.271 & 44.805 & 44.534 & 44.033 & 43.159 \\
\hline MA & 160.172 & 155.260 & 160.604 & 165.663 & 173.671 & 178.047 & 182.891 & 189.784 \\
\hline $\mathrm{PI}$ & 72.443 & 631.35 & 66.235 & 69.275 & 70.353 & 66.282 & 73.401 & 75.594 \\
\hline CE & 232.858 & 224.743 & 235.022 & 238.942 & 241.862 & 238.752 & 239.826 & 250.168 \\
\hline RN & 66.918 & 628.27 & 63.434 & 63.925 & 63.182 & 61.680 & 59.938 & 60.260 \\
\hline PB & 68.566 & 65.581 & 66.409 & 70.204 & 71.620 & 72.257 & 72.077 & 76.237 \\
\hline PE & 175.185 & 171.361 & 179.972 & 191.260 & 201.629 & 210.039 & 213.052 & 219.304 \\
\hline $\mathrm{AL}$ & 56.688 & 53.131 & 56.393 & 58.522 & 60.313 & 61.341 & 62.447 & 64.134 \\
\hline SE & 36.271 & 32.770 & 35.245 & 36.764 & 37.575 & 38.903 & 39.527 & 40.171 \\
\hline BA & 303.060 & 278.183 & 288.072 & 285.352 & 292.076 & 292.438 & 302.631 & 313.275 \\
\hline MG & 481.555 & 498.522 & 527.592 & 538.842 & 544.510 & 544.799 & 549.990 & 572.952 \\
\hline ES & 79.989 & 78.499 & 83.040 & 84.336 & 85.333 & 85.386 & 84.994 & 83.831 \\
\hline RJ & 276.430 & 287.227 & 296.154 & 299.292 & 314.866 & 328.514 & 331.790 & 334.248 \\
\hline SP & 1.153 .250 & 1.207 .141 & 1.231 .108 & 1.232 .674 & 1.244 .846 & 1.252 .107 & 1.204 .560 & 1.245 .933 \\
\hline PR & 269.362 & 277.792 & 282.536 & 282.352 & 279.341 & 275.198 & 275.778 & 277.036 \\
\hline SC & 145.965 & 150.893 & 153.594 & 155.692 & 168.896 & 172.214 & 165.505 & 162.797 \\
\hline RS & 228.799 & 233.527 & 237.459 & 240.110 & 239.521 & 242.949 & 247.241 & 245.043 \\
\hline MS & 50.772 & 56.880 & 56.805 & 56.577 & 57.113 & 57.121 & 57.747 & 56.886 \\
\hline MT & 75.733 & 78.969 & 88.286 & 95.050 & 99.745 & 100.144 & 101.279 & $99 / 142$ \\
\hline GO & 143.188 & 145.712 & 148.620 & 149.801 & 151.818 & 154.806 & 158.874 & 156.982 \\
\hline DF & 56.910 & 59.508 & 62.830 & 63.691 & 62.274 & 63.562 & 64.637 & 63.439 \\
\hline Brasil & 4.489 .585 & 4.540 .113 & 4.697.785 & 4.772 .788 & 4.875 .566 & 4.921 .585 & 4.924 .378 & 5.035 .028 \\
\hline
\end{tabular}

Fonte: Inep. Microdados Censo Escolar 2009; 2010; 2011; 2012; 2013; 2014; 2015; 2016 (2017a)

sido acompanhada de segmentação. Para confirmar essa ocorrência, no entanto, as informações coligidas são insuficientes, uma vez que não é possível atestar que tenha-se verificado alguma hierarquização entre uma e outra modalidade de oferta 
Quadro 1 - Taxa de crescimento da matrícula das pessoas entre 15 e 17 anos no Ensino Médio por Unidade da Federação - dependência administrativa estadual 2009-2016

\begin{tabular}{|c|c|}
\hline Unidade da Federação & Taxa de crescimento 2009-2016 \\
\hline Rondônia & $12,4 \%$ \\
\hline Acre & $36,8 \%$ \\
\hline Amazonas & $42,2 \%$ \\
\hline Roraima & $34,6 \%$ \\
\hline Pará & $25,7 \%$ \\
\hline Amapá & $13,4 \%$ \\
\hline Tocantins & $6,0 \%$ \\
\hline Maranhão & $18,5 \%$ \\
\hline Piauí & $4,3 \%$ \\
\hline Ceará & $7,4 \%$ \\
\hline Rio Grande do Norte & $-9,9 \%$ \\
\hline Paraíba & $11,2 \%$ \\
\hline Pernambuco & $25,2 \%$ \\
\hline Alagoas & $13,1 \%$ \\
\hline Sergipe & $10,7 \%$ \\
\hline Bahia & $3,4 \%$ \\
\hline Minas Gerais & $19,0 \%$ \\
\hline Espírito Santo & $4,8 \%$ \\
\hline Rio de Janeiro & $20,9 \%$ \\
\hline São Paulo & $8,0 \%$ \\
\hline Paraná & $2,8 \%$ \\
\hline Santa Catarina & $11,5 \%$ \\
\hline Rio Grande do Sul & $7,1 \%$ \\
\hline Mato Grosso do Sul & $12,1 \%$ \\
\hline Mato Grosso & $30,1 \%$ \\
\hline Goiás & $9,6 \%$ \\
\hline Distrito Federal & $11,5 \%$ \\
\hline Brasil & $12,1 \%$ \\
\hline
\end{tabular}

Fonte: Inep. Microdados Censo Escolar 2009; 2010; 2011; 2012; 2013; 2014; 2015; 2016 (2017a)

baseada na origem social e/ou nas trajetórias escolares pregressas dos estudantes, ainda que se trate de formação distinta para a mesma etapa. Esta última situação, no entanto, não se pode confirmar, pois, conforme assinala Minhoto (2008, p. 45), "o sistema educacional segmentado é aquele que oferece caminhos paralelos de 
estudos, separados por barreiras institucionais, pelo currículo e por diferenças de origem social dos estudantes", e, especialmente, esta última situação não foi contemplada no levantamento realizado.

Pelo menos em uma situação é possível indicar que a ampliação do acesso ao Ensino Médio veio acompanhada de segmentação. É o caso da diversificação de trajetória com o aumento da matrícula na modalidade da Educação de Jovens e Adultos (EJA), incentivada pela mudança trazida pela Lei de Diretrizes e Bases da Educação, Lei n ${ }^{\circ}$ 9.394/96 (BRASIL, 1996), ao admitir a idade mínima de 18 anos para cursar o Ensino Médio nessa modalidade. Segundo o Censo Escolar de 1997, na modalidade EJA/Ensino Médio, constavam 390.925 matrículas. Em 2016, totalizavam 1.270.198 na EJA não profissional e 39.060 na EJA integrada à Educação Profissional, uma taxa de crescimento da ordem de $234 \%$.

Em que pese o considerável crescimento da taxa líquida de matrícula no Ensino Médio, constata-se, em 2016, o número expressivo de jovens sem qualquer vínculo escolar. Ao menos uma parte ingressou no Ensino Médio e desistiu. Observada a distribuição da matrícula pelos anos/séries, os dados mostram que o abandono escolar é expressivamente maior do primeiro para o segundo ano, se comparados com a passagem do segundo para o terceiro. Também a reprovação é fator de desistência e explica, ao menos em parte, o número de jovens de 15 a 17 anos que desistem da escola. $\mathrm{O}$ abandono escolar, nessa etapa da Educação Básica, foi da ordem dos $16 \%$ no país naquele ano, com maior incidência nas regiões Norte e Nordeste, e entre pretos e pardos (IBGE, 2016). Os dados da Pnad 2016 mostram, ainda, que, enquanto 75\% dos jovens do quartil mais rico da população estão matriculados, somente $44,2 \%$ do quartil mais pobre encontra-se na etapa. No que se refere à distinção de raça/cor/etnia, em 2016, a taxa líquida de matrícula entre brancos era de $70,7 \%$, entre pardos era de 55,3\% e entre pretos era de 55,8\% (IBGE, 2017). Esse quadro indica a manutenção da desigualdade de acesso à última etapa da Educação Básica.

A ampliação do direito à Educação, assegurada por meio da $\mathrm{EC} \mathrm{n} \mathrm{n}^{\circ}$ 59/2019, no que diz respeito ao Ensino Médio, como visto na movimentação da matrícula, denuncia um conjunto de tensões, desde aquela mencionada no início do texto com base em Chauí (1989), por meio do que se pode compreender que a positivação do direito, ainda que necessária na medida em que "constrange" a realidade, em face de seu não cumprimento, sinaliza para a necessidade de que se mantenha 
no horizonte sua exigibilidade e se envidem esforços no sentido de fazer valer o disposto constitucional.

Vale mencionar outro aspecto das referidas tensões. Aprovada recentemente, a reforma do Ensino Médio, que se inicia pela Medida Provisória n ${ }^{\circ} 746 / 16$, e é convertida na Lei ${ }^{\circ}$ 13.415/17 (BRASIL, 2017), conduz, no cenário identificado na pesquisa, à pergunta: em que medida as mudanças em curso constituem-se potentes para superar o quadro de inclusão/exclusão identificado? A análise do que é proposto como reformulação da última etapa da Educação Básica sugere que, não apenas tais conflitos não são apaziguados, mas podem se ver agravados. É o que se pode depreender, por exemplo, do que afirmam Ferreira e Ramos (2018), ao mencionar a proposição da lei acerca da formação técnica e profissional como um dos itinerários formativos:

Nessa composição, algumas consequências podem ser inferidas, como, por exemplo, de o jovem de baixa renda optar pelo ensino técnico para garantir o acesso ao mercado de trabalho com mais agilidade. Isso pode gerar, a longo prazo, retenção de estudantes no nível médio com formação técnica, justificando uma baixa remuneração, mão de obra desqualificada, dentre outros aspectos (p. 1191).

O Ensino Médio possui uma tradição curricular vinculada aos processos seletivos para acesso à Educação Superior. A organização em disciplinas estanques e um ensino que prioriza a memorização têm sido apontados como possíveis causas do abandono escolar e do desinteresse dos jovens pela escola (DAYRELL; JESUS, 2016). A centralidade das políticas curriculares nos últimos 20 anos são, provavelmente, um efeito dessas constatações, além de evidenciar as já mencionadas disputas em torno de suas finalidades e formas de organização. No entanto, a ampliação do acesso, da permanência e da conclusão passam pelo atendimento de um leque de necessidades que, aliadas às mudanças curriculares, poderiam compor um conjunto articulado de políticas capazes de garantir, efetivamente, o direito à Educação.

No contexto da reforma, merece destaque a argumentação oficial em torno da necessidade de uma Base Nacional Comum Curricular (BNCC) e que essa seria capaz de resolver os dilemas da escola de Nível Médio. Ferreira e Ramos (2018) indagam em que medida "o objetivo seria realmente direcionar a aprendizagem para conhecimentos que interessaria ao jovem" (p. 1189). Silva (2018) alerta que dentre as finalidades de uma base curricular tão padronizada e minuciosamente prescrita estaria o maior controle por parte do Estado sobre o que fazem as 
escolas, haja vista que a BNCC servirá de referência para as avaliações em larga escala, nacionais (Enem, Prova Brasil) e internacionais (Programa Internacional de Avaliação de Estudantes - Pisa). A listagem de objetivos e competências responderia, assim, muito mais à consecução dessas formas de controle de modo a adequá-las aos exames, do que em oferecer respostas aos modos de organização pedagógica e curricular e torná-los mais capazes de enfrentar o quadro de abandono e desistência que caracteriza a etapa. Este cenário indica, portanto, para novos pontos de tensões entre o direito proclamado e sua realização.

\section{Considerações Finais}

No Brasil, o binômio inclusão/exclusão é marca histórica do sistema educacional. O século XX e o processo de urbanização e industrialização, ao mesmo tempo em que pressionava pela ampliação da escolaridade da população, continha o acesso pela forma distributiva e desigual com que se ingressava no sistema escolar. A desigual inclusão nos níveis escolares, bem como sua distribuição pelo território brasileiro e entre classes sociais e raça/etnia, compõe um quadro histórico de afirmação/negação do direito à Educação. Neste artigo, com base nos conceitos de inclusão, progressividade e segmentação, os dados coligidos foram interpretados e discutidos de modo a evidenciar processos de produção de maior ou menor desigualdade de acesso ao Ensino Médio e situados no contexto da ampliação do direito à Educação.

A expansão da obrigatoriedade escolar de quatro para oito anos, em 1971 (BRASIL, 1971), e o consequente aumento da inclusão educacional, ao longo dos últimos 30 anos, no Ensino Fundamental, que ampliou a conclusão da escolaridade nesta etapa, pressionou a ampliação do acesso ao Ensino Médio, o que passa a verificar-se a partir de meados da década de 1990. Quando observada a situação do Ensino Médio, a cada ano os dados do Censo Escolar, desde 2004, indicam decréscimo da matrícula. Esse cenário, associado à mudança constitucional de 2009, que torna obrigatório a inclusão no sistema escolar de toda a população entre quatro e 17 anos, sinalizava para um aparente paradoxo. Como a matrícula diminui se a legislação indica a ampliação? As constatações da pesquisa, no entanto, esclarecem que a diminuição, ano a ano, da matrícula incide sobre as pessoas de 18 anos ou mais, que já encontram-se fora da idade escolar obrigatória. Ainda assim, é expressivo o número da matrícula no Ensino Médio de pessoas com 18 anos ou mais. Em 2016, somavam 1.854 .000 ou 22,8\%, o que indica que a distorção idade-série permanece como característica da etapa.

A matrícula no Ensino Médio, para a faixa etária de 15 a 17 anos, cresce entre 2009 e 2016 em todas as Unidades da Federação nas dependências administrativas 
estadual e federal. Nas redes estaduais, o aumento médio é de $12,7 \%$ e na rede federal é de $102,4 \%$. O percentual de crescimento é consideravelmente maior na dependência administrativa federal - onde se oferece Educação Profissional Técnica de Nível Médio - portanto, para a faixa etária de 15 a 17 anos, os dados atestam inclusão e progressividade, pela incorporação de um número expressivo de jovens das regiões mais pobres do país, excluídos do acesso em períodos anteriores. Sugerem uma possível ocorrência de segmentação, considerando o elevado crescimento na oferta profissionalizante. Ainda assim, verifica-se uma considerável distância com relação à universalização inscrita na Meta 3 do PNE.

Nesse contexto é que tem início a atual reforma pela Lei $n^{\circ}$ 13.415/17 (BRASIL, 2017). Desperta a atenção o fato de ser, ela mesma, resultado das disputas que se vêm alimentando, sobretudo nos últimos 20 anos, acerca das finalidades e formas de organização do Ensino Médio. Tais contendas, muito provavelmente, devem-se ao maior acesso da juventude brasileira à etapa final da Educação Básica. Entre 1996 e 2016, o Conselho Nacional de Educação exarou duas Resoluções distintas para a etapa (Resolução CNE/CEB n ${ }^{\circ}$ 03/1998 [BRASIL, 1998] e Resolução n ${ }^{\circ}$ 02/2012 [BRASIL, 2012]), além das diretrizes para a modalidade Educação Profissional Técnica de Nível Médio. O executivo exarou dois decretos sobre a modalidade de Educação Profissional ( $\mathrm{n}^{\circ} 2.208 / 97$ e $\mathrm{n}^{\circ}$ 5.154/2004). O Congresso Nacional formulou um Projeto de Lei (PL n $\left.{ }^{\circ} 6840 / 2013\right)$ que não chegou ir a plenário. O Ministério da Educação implementou um programa que visava à reformulação curricular nas redes estaduais (Programa Ensino Médio Inovador - ProEMI), além dos documentos orientadores das avaliações nacionais, que culminaram por incidir, também, na organização curricular das escolas. Os impactos dessas alterações no cenário da obrigação do Estado em assegurar a efetiva ampliação do acesso fez emergir novos pontos de tensão e de constrangimento diante de um direito proclamado, mas ainda distante de ser realizado. 


\title{
Expansion of compulsory schooling in Brazil: what happened to Secondary Education?
}

\begin{abstract}
This article is the result of a research that had as object of study the expansion of the right to secondary education for 15 to 17 year old youngsters. Its legal references are the determinations of the Federal Constitution, through the Constitutional Amendment No. 59/2009, the Guidelines and Base Law (law 9.394/1996) and the National Education Plan 2014-2024 (Law $n^{\circ} 13.005 / 2014$ ). The study considers that compulsory schooling is a prerequisite for the universalization of access to education. We analyzed enrolment in the last stage of Basic Education, in the period between 2009 and 2016. The primary sources for data collection were the National Household Sample Survey (Pnad), considering the 27 Units of the Federation. The analysis indicates that, during the period, there was a process of educational inclusion of this age group, especially in the states with the highest exclusion. In the state's networks, the average increase is $12.7 \%$ and in the federal network is $102.4 \%$.
\end{abstract}

Keywords: High School. Basic education. School obligation. Educational inclusion. Amendment 59/2009.

\section{Ampliación de la obligatoriedad escolar en Brasil: ¿qué sucedió con la Educación Secundaria?}

\section{Resumen}

Este artículo es el resultado de una investigación que tuvo como objeto de estudio la ampliación del derecho a la educación considerando el acceso a la enseñanza media para jóvenes de 15 a 17 años. Tiene como referencia legal lo establecido por la Constitución Federal a partir de la Enmienda Constitucional (EC) 59/2009, la Ley de Directrices y Bases de la Educación (Ley 3.394/1996) y el Plan Nacional de Educación 2014-2024 (Ley 13.005/2014). La condición de la obligatoriedad escolar se ve como un presupuesto para la universalización del acceso. Se analiza el movimiento de la matrícula en la última etapa de la Educación Básica en el periodo comprendido entre 2009 y 2016. Considera que un presupuesto para la universalización del acceso a la educación es la condición de la obligatoriedad escolar. Se analiza el movimiento de la matrícula en la última etapa de la Educación Básica, en el período comprendido entre 2009 y 2016. Las fuentes primarias para la recolección de los datos fueron el Censo Escolar de la Educación Básica y la Encuesta Nacional por Muestra de Domicilio (Pnad), apreciando las 27 Unidades de la Federación. El análisis indica que hubo, en el periodo, un proceso de inclusión educativa de la franja etaria, sobre todo en los Estados que presentaban mayor exclusión. En las redes estatales, el aumento promedio de la matrícula fue del $12,7 \%$ y en la red federal del 102,4\%.

Palabras clave: Educación Secundaria. Educación Básica. Obligatoriedad escolar. Inclusión educativa. EC 59/2009. 


\section{Referências}

BOBBIO, N. A era dos direitos. 9. ed. Rio de Janeiro: Campus, 1992.

BRASIL. Constituição da República Federativa do Brasil de 1988. Brasília, DF: Senado Federal, 1988. Disponível em: http://www.planalto.gov.br/ ccivil_03/Constituicao/Constituicao.htm. Acesso em: 25 jul. 2018.

BRASIL. Decreto $\mathrm{n}^{\circ} 2.208$, de 17 de abril de 1997. Regulamenta o parágrafo $2^{\circ}$ do art. 36 e os artigos 39 a 42 da Lei $n^{\circ} 9.394$, de 20 de dezembro de 1996, que estabelece as diretrizes e bases da educação nacional. Diário Oficial da União, Brasília, DF, 18 abr. 1997.

BRASIL. Decreto $\mathrm{n}^{\circ} 5.154$, de 23 de julho de 2004. Regulamenta o $\S 2^{\circ}$ do art. 36 e os arts. 39 a 41 da lei $n^{\circ} 9.394$, de 20 de dezembro de 1996, que estabelece as diretrizes e bases da educação nacional, e dá outras providências. Diário Oficial da União, Brasília, DF, 26 jul. 2004.

BRASIL. Emenda constitucional n ${ }^{0}$ 59, de 11 de novembro de 2009. Acrescenta $\S 3^{\circ}$ ao art. 76 do Ato das Disposições Constitucionais Transitórias; dá nova redação aos incisos I e VII do art. 208 , ao $\S 4^{\circ}$ do art. 211 e ao $\S 3^{\circ}$ do art. 212 e ao caput do art. 214, com a inserção neste dispositivo de inciso VI, da Constituição Federal. Diário Oficial da União, Brasília, DF, 12 nov. 2009.

BRASIL. Lei $\mathrm{n}^{\circ}$ 5.692, de 11 de agosto de 1971. Fixa Diretrizes e Bases para o Ensino de $1^{\circ}$ e $2^{\circ}$ graus e dá outras providências. Diário Oficial da União, Brasília, DF, 12 ago. 1971.

BRASIL. Lei n ${ }^{\circ} 9.394$, de 20 de dezembro de 1996. Estabelece as diretrizes e bases da educação nacional. Diário Oficial da União, Brasília, DF, 23 dez. 1996.

BRASIL. Lei n ${ }^{\circ} 10.172$, de 9 de janeiro de 2001. Estabelece o Plano Nacional de Educação 2001-2011. Diário Oficial da União, Brasília, DF, 10 jan. 2001

BRASIL. Lei n ${ }^{\circ} 13.005$, de 24 de junho de 2014. Aprova o Plano Nacional de Educação - PNE e dá outras providências. Diário Oficial da União, Brasília, DF, 26 jun. 2014.

BRASIL. Lei $\mathrm{n}^{\circ} 13.415$, de 16 de fevereiro de 2017. Altera as Leis $\mathrm{n}^{\circ}$ 9.394, de 20 de dezembro de 1996, que estabelece as diretrizes e bases da educação nacional, e 11.494, de 20 de junho 2007, que regulamenta o Fundo de Manutenção e desenvolvimento da Educação Básica e de Valorização dos Profissionais da Educação, a Consolidação das Leis do Trabalho - CLT, aprovada pelo Decreto-Lei $n^{\circ} 5.452$, de $1^{\circ}$ de maio de 1943, e o Decreto-Lei $\mathrm{n}^{\circ} 236$, de 28 de fevereiro de 1967; revoga a Lei $\mathrm{n}^{\circ} 11.161$, de 5 de agosto de 2005; e institui a Política de Fomento à Implementação de Escolas de Ensino Médio em tempo integral. Diário Oficial da União, Brasília, DF, 17 fev. 2017. 
BRASIL. Ministério da Educação. Conselho Nacional de Educação. Resolução CEB n ${ }^{\circ}$ 2, 30 de janeiro de 2012. Define Diretrizes Curriculares Nacionais para o Ensino Médio. Diário Oficial da União, Brasília, DF, 31 jan. 2012.

BRASIL. Ministério da Educação. Conselho Nacional de Educação. Resolução CEB nº 3, de 26 de junho de 1998. Institui as Diretrizes Curriculares Nacionais para o Ensino Médio. Diário Oficial da União, Brasília, DF, 5 ago. 1998.

BRITO, M. M. A. A dependência na origem: desigualdades no sistema educacional brasileiro e a estruturação social das oportunidades. 2014. Tese (Doutorado em Sociologia) - Faculdade de Filosofia, Letras e Ciências Humanas, Universidade de São Paulo, São Paulo, 2014.

CHAUÍ, M. Cultura e democracia. 8. ed. São Paulo: Cortez, 1989.

DAYRELL, J. T.; JESUS, R. E. Juventude, ensino médio e os processos de exclusão escolar. Educação \& Sociedade, Campinas, v. 37, n. 135, p. 407-423, abr./jun. 2016. https://doi.org/10.1590/ES0101-73302016151533

FERRAJOLI, L. Direito e razão: teoria do garantismo penal. São Paulo: Revista dos Tribunais, 2002.

FERREIRA, R. A.; RAMOS, L. O. L. O projeto da MP n ${ }^{\circ} 746$ : entre o discurso e o percurso de um novo ensino médio. Ensaio: Avaliação e Políticas Públicas em Educação, Rio de Janeiro, v. 26, n. 101, p. 1176-1196, out./dez. 2018. https://doi.org/10.1590/s0104-40362018002601295

GOMES, C. A. O ensino médio ou a história do patinho feio recontada. Brasília, DF: Universa, 2000.

INSTITUTO BRASILEIRO DE GEOGRAFIA E ESTATÍSTICA - IBGE. Séries estatísticas: consulta on line. Brasília, DF, 2007. Disponível em: http:// www.seriesestatisticas.ibge.gov.br/series.aspx?vcodigo=PD164. Acesso em: 8 mar. 2018.

INSTITUTO BRASILEIRO DE GEOGRAFIA E ESTATÍSTICA - IBGE. Pesquisa nacional por amostra de domicílio Pnad: 2009 a 2016. Brasília, DF, 2017. Disponível em: https://dadoseducacionais.c3sl.ufpr.br/\#/indicadores/ populacao. Acesso em: 6 mar. 2018.

INSTITUTO NACIONAL DE ESTUDOS E PESQUISAS EDUCACIONAIS ANÍSIO TEIXEIRA - Inep. Microdados/censo escolar da educação básica 2008-2017. Brasília, DF, 2017a. Disponível em: www.inep.gov.br. Acesso em: 3 abr. 2018. 
INSTITUTO NACIONAL DE ESTUDOS E PESQUISAS EDUCACIONAIS ANÍSIO TEIXEIRA - Inep. Panorama da educação: destaques do education at glance 2016. Brasília, DF, 2016.

KRAWCZYK, N.; SILVA, C. J. O. Desigualdades educacionais no ensino médio brasileiro: uma análise de perfil socioeconômico de jovens que realizaram o exame nacional do ensino médio. Sensos-e, [s. l.] v. 4, n. 1, p. 12-23, 2017.

MINHOTO, M. A. P. Articulação entre primário e secundário na era Vargas: crítica do papel do Estado. Educação e Pesquisa, São Paulo, v. 34, n. 3, p. 449-463, set./dez. 2008.

OLIVEIRA, R. P. O direito à educação. In: OLIVEIRA, R. P.; ADRIÃO, T. Gestão, financiamento e direito à educação: análise da constituição Federal e da LDB. 3. ed. São Paulo: Xamã, 2002. paginação.

OLIVEIRA, R. P.; ARAÚJO, G. C. Qualidade do ensino: uma nova dimensão da luta pelo direito à educação. Revista Brasileira de Educação, Rio de Janeiro, n. 28, p. 5-23, jan./abr. 2005. https://doi.org/10.1590/S1413-24782005000100002

SILVA, M. R. A BNCC da reforma do ensino médio: o resgate de um empoeirado discurso. Educação em Revista, Belo Horizonte, v. 34, e214130, 2018. https://doi.org/10.1590/0102-4698214130

SILVEIRA, A. D. Conflitos e consensos na exigibilidade judicial do direito à educação básica. Educação \& Sociedade, Campinas, v. 34, n. 123, p. 371-387, abr./jun. 2013. https://doi.org/10.1590/S0101-73302013000200003

VIÑAO, A. Sistemas educativos, culturas escolares y reformas: continuidades y cambios. Madrid: Morata, 2002. (Colección pedagogía: razones y propuestas educativas, 10).

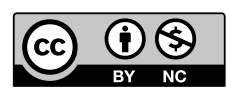

\section{Informações da autora}

Monica Ribeiro da Silva: Doutora em Educação pela Pontifícia Universidade Católica de São Paulo. Professora do Programa de Pós-Graduação em Educação da Universidade Federal do Paraná. Contato: monicars@ufpr.br

(iD) https://orcid.org/0000-0002-1729-8742 